\title{
GLOBALIZAÇÃO E CRISE CONSTITUCIONAL
}

\author{
Flávio dino de Castro e Costa*
}

\section{1 - Introdução}

O ano de 1997 no Brasil foi marcado pelo aprofundamento da crise de diversos conceitos e institutos consagrados pela Constituição de 1988. Vários são os indicadores de tal fenômeno: a falência dos sistemas estaduais de segurança, atingindo seu apogeu nos conflitos envolvendo policiais armados em praças públicas; a generalização da sensação de impunidade; a descrença na aptidão do Judiciário para assegurar a igualdade de todos perante a lei; a incapacidade de negociar-se uma solução duradoura para a questão agrária; o absoluto descalabro na saúde pública - "direito de todos e dever do Estado", segundo o art. 196 da CF.

Nestes episódios evidenciou-se que há uma significativa dimensão jurídica na crise brasileira, caracterizada pela desconformidade entre as condutas dos diferentes sujeitos neles envolvidos e o que seria previsível, segundo as regras jurídicas vigentes. Daí porque, em todos os momentos assinalados, invariavelmente o debate desembocou em propostas de emendas constitucionais ou de novas leis (reforma do Judiciário e das Polícias; outras fontes de financiamento para a saúde pública; rito sumário para desapropriações etc.).

A profundidade desta crise jurídica pode ser mensurada pela freqüência com que as novas regras exigidas têm natureza constitucional, implicando um permanente movimento constituinte no Brasil durante toda esta década.

Algumas análises atribuem esta autêntica crise constitucional a fatores pertinentes, porém periféricos neste momento, tais como a escassa tradição democrática no nosso país ou o formato adotado pelo constituinte de 1987 para a nova Carta ambivalente, detalhista etc.

Trilhando vereda diversa, este texto pretende destacar o especial relevo que circunstâncias históricas ora vivenciadas, como a globalização e a exclusão social, têm para a apontada crise constitucional.

* Juiz Federal e Professor do Departamento de Direito da UFMA.

R. Dir. Adm.,

Rio de Janeiro, 211: 233-239, jan./mar. 1998 


\section{2 - A globalização e o estado nacional}

Relevante realçar, de início, que quando se enfoca a globalização não se está tratando de fenômeno recente, tendo em vista que o caráter mundial dos sistemas de produção e consumo, com a progressiva interdependência entre os mercados, vêm se delineando ao longo de pelo menos cinco séculos.

No entanto, impossível deixar de reconhecer singularidades na fase presente deste processo de mundialização. Basta que se compare a velocidade e a extensão das repercussões da quebra da Bolsa de Nova lorque em 1929 com a atual "crise asiática" (Tailândia, Hong Kong) para que se constate a pujança da transnacionalização em nossos dias.

A principal singularidade a ser sublinhada reside no próprio fato de falar-se em transnacionalização, o que representa ir além da noção de internacionalização, na medida em que este último termo pressupõe a permanência do conceito de nação (inter $=$ ação recíproca), enquanto que o primeiro na verdade sinaliza para sua superação (trans $=$ além, através de).

De fato, a globalização ora vivenciada põe em xeque o paradigma de Estado adotado pelo constitucionalismo nos últimos dois séculos, posto que, transnacionalizaram-se, junto com a economia, as fontes de produção normativa, cujo controle sempre foi visto como fundamental para a existência de uma Nação soberana.

Perdeu assim o Estado, do ponto de vista prático, o monopólio da implantação da juridicidade, diante do grande poder ostentado pelos conglomerados econômicos. Os indicadores que permitem demonstrar a veracidade desta afirmação são vários.

Considere-se, por exemplo, que os dez maiores grupos empresariais do mundo faturam anualmente 1 trilhão e 400 bilhões de dólares, o que é superior à soma do Produto Interno Bruto dos países do Mercosul. Esta realidade econômica confere a eles um poder formidável, inclusive para impor políticas aos Estados "soberanos".

Neste passo, não é exagerado afirmar que hoje os conglomerados econômicos escolhem a juridicidade a que serão submetidos. Caso as leis tributárias, ambientais ou trabalhistas em vigor em determinado país não mais os agradem - e se o sistema jurídico tiver eficácia suficiente para combater os comportamentos ilícitos - é relativamente simples a eles modificar a rota dos seus investimentos, até mesmo para forçar a revisão de tais regras "incômodas".

Uma excelente síntese desta nova realidade foi apresentada pelo atual Presidente da República, ao discursar no México, em fevereiro deste ano, conforme transcrito pela Folha de São Paulo: "os mercados de capitais passaram a atuar como verdadeiros vigilantes das gestões nacionais. Qualquer medida por mais correta do ponto de vista interno, que possa sinalizar um passo em falso ou contrariar os interesses dos investidores externos tem como consequiência a revoada dos capitais de curto prazo, com sérios efeitos para a saúde do sistema financeiro nacional. A ortodoxia ou conservadorismo dessa espécie de Tribunal imaterial, porém influente, traz limitações à capacidade de operar dos governantes."

Mesmo a faceta mais primária de um Estado soberano - a repressão dos crimes ocorridos em suas fronteiras - é desafiada pelo processo em análise. 
Por primeiro, as difíceis condições de sobrevivência do povo nestes tempos de "inempregabilidade" - decorrente da reestruturação produtiva global - eleva brutalmente a criminalidade "convencional", aprofundando a baixa credibilidade das instituições estatais encarregadas do seu combate, especialmente o aparato policial.

Em segundo lugar, a globalização transnacionaliza também os crimes, por exemplo com a utilização do mercado financeiro para a lavagem de dinheiro oriundo do tráfico de entorpecentes ou da exploração sexual de crianças e de mulheres. Neste contexto, assiste razão ao Chefe de Serviços do Departamento Nacional Criminal da Inglaterra, ao declarar para o "Financial Times" (ed. 29/05/97) que há atualmente a necessidade de uma nova área de atuação policial, em função de uma criminalidade que envolve não as ruas das cidades, mas as "rodovias de informação". Alertava ele então que os mecanismos instantâneos de comunicação através do planeta são grandes facilitadores da atividade do crime organizado em "setores de ponta", sem que o Estado seja capaz de fiscalizá-lo e puni-lo, impondo sua soberania.

Em face desta dimensão, é natural que tal crise atinja todas as instituiçōes que compõem a essência deste modelo de Estado que dominou o imaginário de seguidas gerações de juristas - o Estado de Direito.

É o caso do Parlamento, progressivamente posto à margem dos processos decisórios, tendo em vista que qualquer debate entre teses contrárias pode toldar os valores mais estimados pelos grandes investidores: certeza e velocidade. Daí porque não ser correto atribuir exclusivamente à personalidade autoritária deste ou daquele Chefe do Poder Executivo a ocorrência de abusos na edição de medidas provisórias. Estas, na verdade, muitas vezes são editadas e reeditadas por serem, paradoxalmente, os meios mais seguros e ágeis para que os intelectuais da "nova ordem" - ocupando o ápice da burocracia estatal - imponham novas normas de conduta, de acordo, sobretudo, com os interesses econômicos dominantes.

Assim também o Judiciário - já visto como parcial e fraco diante dos poderosos - pode ter sua imagem ainda mais deteriorada, caso prevaleçam determinadas propostas para sua reforma, apregoadas em nome de solucionar a sua crise. Mitigar os amplos controles de constitucionalidade das leis e de legalidade dos atos administrativos - hoje formalmente possíveis de serem exercidos pelos magistrados é algo que diminuirá acentuadamente o poder material dos Juízes. Do mesmo modo, um enfraquecimento do Poder Judiciário ocorrerá se forem generalizadas as proclamadas soluçōes "alternativas" para os macroconflitos, como os recentemente criados Juízos Arbitrais. Em ambos os casos, os valores que inspiram tais propostas são, sobretudo, a previsibilidade e a velocidade na solução das controvérsias, portanto os mesmos que conduzem à apropriação da função legislativa pelo Poder Executivo, confö̈rme assinalado.

Todavia, não são somente estes aspectos do processo de globalização que conduzem à crise institucional (e portanto constitucional) que atravessamos nesta década, cujos principais sintomas foram acima abordados. A crescente concentração de riqueza, com o conseqüente alargamento da faixa dos excluídos, também entra em choque com a Constituição vigente, conforme analisaremos em seguida 
Pessoas que necessitam de determinadas prestações positivas dos vários sistemas — jurídico, político, econômico - e não as obtêm de maneira satisfatória, sempre houve. Reconhecer, portanto, que existem excluidos, assim como dito em relação à globalização, não constitui nenhuma novidade.

Em 1835, Tocqueville apud Weffort (1989, p. 177-178), em "A Democracia na América", tecia considerações pertinentes a este assunto, assinalando:

“ (...) à medida que o principio da divisão do trabalho é mais plenamente aplicado, o operário se torna mais frágil, mais limitado e mais dependente. A arte faz progressos, o artesão regride. Por outro lado, à medida que se descobre de maneira mais clara que os produtos de uma indústria são tão mais perfeitos e tão menos caros quanto mais ampla a fábrica e maior o capital, homens muito ricos e muito esclarecidos se apresentam para explorar indústrias que, até então, tinham sido entregues a artesãos ignorantes ou desqualificados. São fascinados pela grandeza dos esforços necessários e pela amplitude dos resultados almejados.

Assim, portanto, ao mesmo tempo que a ciência industrial rebaixa incessantemente a classe dos operários, ela eleva a dos mestres.(...) É por isso que, quando remontamos à origem, parece que vemos a aristocracia brotar, por um esforço natural, do seio mesmo da democracia.Mas esta aristocracia não se assemelha em nada àquelas que a precederam.(...) A aristocracia territorial dos séculos passados foi obrigada pela lei, ou se imaginava obrigada pelos costumes, a vir em auxilio de seus servidores e a aliviar seus sofrimentos. Mas a aristocracia manufatureira de hoje, depois de ter empobrecido e embrutecido os homens de que ela se serve, os entrega, em tempos de crise, à caridade pública para os alimentar. Isto resulta naturalmente daquilo que precede. Entre o operário e o mestre, as relações são freqüentes, mas não há associação verdadeira."

Demonstrava Tocqueville, desta maneira, que a exclusão social derivada da reorganização do sistema de produção então em curso poderia ser, em certo sentido, mais perversa do que a existente no sistema anterior. A diferença, conforme sublinhado, é que anteriormente os "de baixo" estavam incluídos, na proporção de suas importâncias para o funcionamento do sistema.

No entanto, somente na parte final deste século é que a exclusão parece atingir seu ponto máximo, ao desenhar-se de modo claro entre os "bem-postos" a sensação de que há gente sobrando no planeta, seja pela fantástica revolução tecnológica que vivenciamos, seja pelos riscos que o sufrágio universal representa - com sua "subversiva" fórmula "one man, one vote"' Vale dizer: sob a ótica puramente da "utilidade", existem pessoas que não têm nenhum papel social positivọ a desempenhar, servindo somente para ameaçar o sistema de desestabilização - pelo voto "errado", pela violência ou pela rebelião (às vezes, pela mera presença física).

1 Pertinente lembrar, ainda, que uma das diretrizes do modelo fordista, no campo da política de recursos humanos era a concentraçāo de mão-de-obra com reduzida remuneração. Hoje a "nova ordem mundial" sugere, senão impōe, o enxugamento dos quadros de pessoal e terceirizaçāo de atividades consideradas secundárias, reforçando o fenômeno em foco. 
Viviane Forrester (1997, p. 15-18), neste grande manifesto recentemente lançado, intitulado " $O$ Horror Econômico", alertou para os riscos que tal fenômeno implica, destacando:

“...para que se entulhar de escravos, se o trabalho deles é supérfluo? Então, como um eco àquela pergunta que "emergia" mais acima, surge outra que se ouve com temor: será "útil" viver quando não se é lucrativo ao lucro? (...) E se acontecesse de não estarmos mais numa democracia? (...)

O que aconteceria se o "mérito", do qual dependeria mais do que nunca o direito de viver, e esse direito de viver, ele próprio, fossem argüidos e administrados por um regime autoritário?

Já não ignoramos, não podemos ignorar que ao horror nada é impossível, que não há limites para as decisões humanas. Da exploração à exclusão, da exclusão à eliminação, (...) será que essa seqüiência é impensável? Sabemos, por experiência própria, que a barbárie, sempre latente, combina de maneira perfeita com a placidez daquelas maiorias que sabem tão bem amalgamar o pior com a monotonia ambiente."

A mera cogitação desta trágica hipótese-limite, infelizmente revestida de plausibilidade, serve para caracterizar de maneira definitiva o quanto a Constituição vigente é avessa à lógica dominante.

Com efeito, a Carta de 1988 é uma filha "tardia" do constitucionalismo social, posto que moldada com a pretensão de institucionalizar o "Welfare State" no Brasil, no instante em que suas premissas - hegemônicas durante praticamente todo o século XX - eram revistas nos países qualificados como "centrais".

Os constituintes de 1987/1988 agiram movidos pela pretensão de alterar o status $q u o$, atribuindo novas tarefas ao Estado e alargando o próprio conceito de cidadania. Aprovou-se, com tal motivação, uma Constituição dirigente, segundo a expressão consagrada de Canotilho, com o propósito explícito de servir de programa permanente de Governo, impregnado pela idéia de inclusão social (traduzida na enunciação reiterada do compromisso com a justiça, a igualdade, o bem-estar social etc).

Foi o descompasso entre estes intentos e a globalização excludente e concentradora (de riquezas e de poder), consoante demonstrado, que conduziu à atual crise constitucional brasileira.

Retomando-se então a imagem apresentada, conclui-se que a atual crise constitucional decorre do desejo de que aquele filho tardio do constitucionalismo social "amadureça", abandonando os sonhos da adolescência e transformando-se em um adulto plenamente "adaptado" ao seu tempo

\section{A crise constitucional - Perspectivas}

Conforme destacado, a Constituição de 1988 nasceu quando ruiam os pilares sobre os quais se assentaria a sua implementação: Estado nacional forte, ampla mobilização política, extensão da cidadania, inclusão social.

Por esta razão, nunca deixou de ser uma Constituição nominal, como Loewens- 
tein (1983, p. 218) classifica as Constituições que, embora juridicamente válidaś, não são capazes de dirigir o processo político-social ${ }^{2}$.

Poder-se-ia indagar qual a necessidade de procederem-se as reformas constitucionais, se é certo que a Carta em vigor não possui efetividade suficiente para se contrapor ao processo de globalização.

Almeja-se, acima de tudo, eliminar a tensão entre a nova direção imprimida ao desenvolvimento da sociedade e as regras constitucionais vigentes. Trata-se, pois, de, na medida do possível, desjuridicizar dilemas tais como: transnacionalização $x$ Estado nacional, Estado mínimo $x$ Estado intervencionista, cidadania máxima $x$ exclusão social etc.

Com isto, limitar-se-ia a possibilidade de interferência do Poder Judiciário em prol da "velha" ordem - v.g. mediante o controle de constitucionalidade dos atos normativos - além de se retirar parte da eficácia persuasiva de discursos contrahegemônicos, fundados exatamente na defesa do sistema constitucional erigido em $1987 / 1988$.

São vários os desdobramentos possíveis para esta conjuntura. Um deles, sem dúvida, é a consumação das reformas constitucionais em todos os campos (econômico, político, tributário, administrativo, previdenciário, judiciário etc), realizandose assim, de modo pleno, o desejo referido.

Há outros cenários, contudo, que - não excluindo totalmente o processo de reforma constitucional - ancoram-se em alguns eixos diversos dos dominantes.

É fundamental, por exemplo, defender-se a subsistência do Estado nacional com poderio suficiente para contrabalançar essa espécie de neofeudalismo, em que novos suseranos - os grandes grupos econômicos - afirmar-se-iam como fontes primordiais do poder político e da produção normativa.

Isto não significa deixar-se de admitir o reenquadramento do papel do Estado nas sociedades contemporâneas. Afinal, é melhor ter um Estado que seja um excelente regulador do que manter-se um mau gestor de determinadas atividades do mercado. $\mathrm{O}$ que não se pode abdicar é do reconhecimento de que a instância estatal deve preservar poder suficiente para atuar como promotora da cidadania, instrumento de arbitramento dos conflitos sociais e garantidora da extensão do progresso material para os mais amplos setores da sociedade.

Como parte desta meta, é necessário recredibilizar o processo decisório democrático, o que depende, inclusive, das posturas que o Judiciário e o Legislativo adotarão neste período de intensos debates acerca dos caminhos para a superação da crise constitucional analisada.

$2 \mathrm{Na}$ "Teoría de la Constitución", Loewenstein apresenta o que chama de uma classificação ontológica das Constituiçōes, segundo o papel das Cartas escritas na realidade sociopolítica. A constituição normativa É assim caracterizada: "sus normas dominan el proceso político o, a la inversa, el proceso del poder se adapta a las normas de la constitución y se somete a ellas". Quanto à constituição nominal destaca o autor: "una constitución podrá ser jurídicamente válida, pero si la dinámica del proceso político no se adapta a sus normas, la constitución carece de realidad existencial". Finalmente, no que tange a semântica diz: "en lugar de servir a la limitación del poder, la constitución es aquí el instrumento para estabilizar y eternizar la intervención de los dominadores fácticos de la localización del poder político". 
São enormes, portanto, os desafios dos que efetivamente almejam dias mais felizes para os homens. Abdicar do dever de sugerir alternativas é a única postura inaceitável, mormente para os ocupantes de cargos de direção do Estado, como os Magistrados. Tocqueville apud Weffort (1989, p. 184) já nos alertava que "para ser livre, é preciso ser capaz de conceber um empreendimento difícil e nele perseverar (...); para ser livre, é preciso se habituar a uma existência plena de agitação, movimento e perigo; estar constantemente atento e a cada instante dirigir um olhar inquieto ao redor de si: a liberdade tem este prefo."

\section{Bibliografia consultada}

1 - FORRESTER, Viviane. O Horror Econômico. Tradução de Álvaro Lorencini. São Paulo: UNESP, 1997. 154 p. (Ariadne).

2 - LOEWENSTEIN, Karl. Teoría de la Constitución. Traducción y estudio sobre la obra por Alfredo Gallego Anabitarte. 2. ed. Barcelona: Ariel, 1983, 619 p.

3 - WEFFORT, Francisco C. (Org.). Os Clássicos da Política: Burke, Kant, Hegel, Tocqueville, Stuart Mill, Marx. São Paulo: Ática, 1989. V. 2. (Série Fundamentos; 63). 


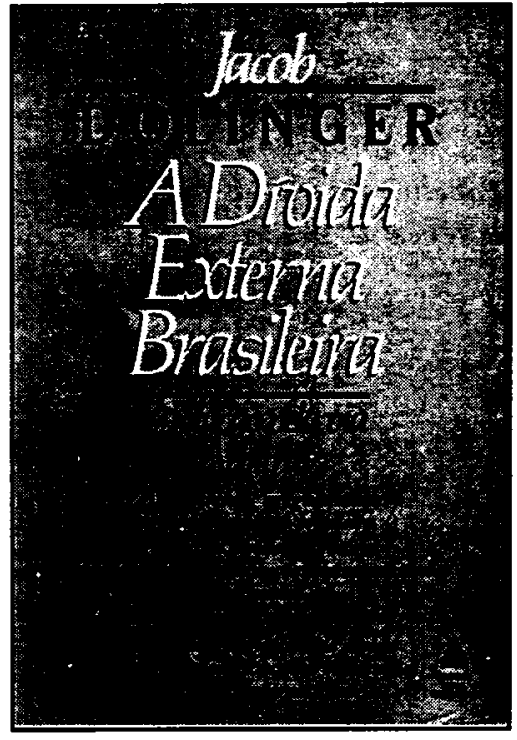

Ref. 0095

Distribuição

Brochura

171 págs.

Form. 14x21

1988

\section{A DÍVIDA EXTERNA BRASILEIRA}

Jacob Dolinger

O livro trata da mais delicada questão da economia brasileira - a divida externa, que abrange problemas econômicos, políticos e sociais e, naturalmente, jurídicos. A Dívida Externa Brasileira estuda, entre outros temas, os aspectos jurídicos das finanças internacionais e a arbitragem como método de solução não litigiosa. Examinando os princípios, regras e convençōes do direito internacional, o autor chegou à conclusão de que uma arbitragem internacional entre o Brasil e os bancos americanos, nossos credores, seria uma soluçāo válida e com possíveis bons resultados. 